\title{
Microbial dysbiosis and disease pathogenesis of endometriosis, could there be a link?
}

\author{
Jessica Puca ${ }^{1}$ and Gerard F. Hoyne ${ }^{2,3,4,5^{*}}$ \\ ${ }^{1}$ School of Arts and Sciences, University of Notre Dame Australia, Fremantle, Western Australia, Australia \\ ${ }^{2}$ School of Health Sciences, University of Notre Dame Australia, Fremantle, Western Australia, Australia \\ ${ }^{3}$ Institute of Health Research, University of Notre Dame Australia, Western Australia, Australia \\ ${ }^{4}$ Centre for Cell Therapy and Regenerative Medicine, School of Medicine and Pharmacology and Harry Perkins \\ Institute of Medical Research, University of Western Australia, Nedlands, Australia
}

${ }^{5}$ Institute for Respiratory Health, Centre for Respiratory Health, School of Medicine and Pharmacology, University of Western Australia, Nedlands, Australia

\begin{abstract}
Endometriosis is an estrogen-dependent inflammatory condition in women that is characterised by the ectopic growth of endometrial glands and stroma outside of the uterine cavity. Although there exists many theories for the pathogenesis of endometriosis, none has been successively confirmed as a direct cause for disease development. The human body comprises a diverse microflora across all tissues that can have fundamental roles in health and disease. The microbial flora in a healthy individual can vary remarkably between anatomical sites due to the physical and chemical properties of specific tissues. This includes the female reproductive tract, notably the vagina, which harbors a microbiota dominated by Lactobacilli species. In addition, a core unique microbiome has been defined for the endometrium that also includes Lactobacilli spp. In this review we examine the possibility that endometriosis could result from microbial dysbiosis, whereby significant changes to the natural microflora within the endometrium could reduce mucosal immune regulation in this tissue with concomitant expansion of pathogenic bacteria that trigger local tissue inflammation that could perpetuate the development of endometrial disease.
\end{abstract}

Keywords: Endometriosis, Retrograde menstruation, Lactobacilli spp., Microbial dysbiosis, Gynaecological diseases.

Accepted on 28 December, 2016

\section{Introduction}

Endometriosis is a disorder characterised by benign, ectopic growth of estrogen-dependent endometrial tissue outside of the uterine cavity, commonly in the pelvic region. The prevalence of endometriosis is more frequent in women of reproductive age and those who exhibit pelvic pain and infertility. Endometriosis seems to be most common in women aged around 25 to 45 years [1-4]. Moreover, 45 to $49 \%$ of women who presented with pelvic pain, 33\% with dysmenorrhea and $42 \%$ of women aged between 25 to 34 years with infertility had endometriosis $[2,5]$. The disorder is generally associated with dysmenorrhoea (painful menstruation), dyspareunia (painful sexual intercourse) dysuria (painful urination), pelvic pain and infertility [6-9]. In addition, risk factors for endometriosis include early menarche and late menopause, short menstrual cycle and heavy menstrual bleeding, along with prolonged exposure to endogenous estrogen and exposure to chemicals that disrupt normal endocrine homeostasis within the reproductive tract $[7,9,10]$.

Endometriosis can be classified based on the anatomical location of lesions and severity and this can assist clinicians with sequential treatment and management of the condition.
Diagnostic methods for the early identification of endometriosis are still lacking which means that clinicians must rely heavily on invasive surgical procedures for confirmation of the disease $[11,12]$. In addition, there a few treatment and management options for patients with endometriosis, and surgical intervention remains the main option for most patients. Curative treatments for the disease are absent and this is due mainly to a poor understanding of the cellular and molecular basis of disease pathogenesis.

Several studies have attempted to measure the impact of endometriosis on the quality of life of affected women and the subsequent cost across countries and ethnicities [13-20]. These studies reveal that the disease bears a significant social, physical, psychological and economic burden on those affected, given that it negatively impacts an affected woman's health related quality of life, reproductive capacity and work productivity. Severe pelvic pain is the predominant contributor to a loss of work productivity among affected women and this can greatly impede other daily activities [19]. Endometriosis thus can have a significant negative impact on a woman's life in a multi-factorial manner which urges a closer examination of the pathogenesis of the disease. 
Citation: Puca J, Hoyne GF. Microbial dysbiosis and disease pathogenesis of endometriosis, could there be a link?. Allied J Med Res 2017;1(1):1-9.

Several theories have been proposed for the pathogenesis of endometriosis, however the contribution of microbial dysbiosis to the development of the disease has been poorly examined. It is now understood that the human body has an extensive microbial flora which is established early in life [21] and each tissue displays a unique microbial flora which is determined by both the physical and chemical properties of the individual tissue [22-24]. Scientists have discovered that the normal microflora can have direct health benefits to the host and if the balance between healthy bacteria and pathogens ensues (i.e. microbial dysbiosis), this can have a direct impact on disease pathogenesis [21]. In addition, the role of the microbiota has extended from the gut and the skin which are the two major mucosal sites of microbial inhabitation. It is now apparent that the microbiota plays an important role in both health and disease in humans and can impact on various body tissues, to the extent that is has been implicated in diseases such as type 2 diabetes [28], autoimmune diseases like rheumatoid arthritis and multiple sclerosis $[29,30]$ and for metabolic diseases such as kwashiorkor [21]. This review will provide an overview of some recent studies which have examined the makeup of the microbial flora of the female reproductive tract but also explore how microbial dysbiosis could provide a link to the development of endometriosis.

Table 1. Current theories on the pathogensis of endometrosis.

\begin{tabular}{|c|c|c|}
\hline Theory & Proposed mechanism of action & References \\
\hline $\begin{array}{l}\text { Retrograde } \\
\text { menstruation }\end{array}$ & $\begin{array}{l}\text { Reflux of endometrial tissue and cells } \\
\text { through the fallopian tubes to the ovaries. }\end{array}$ & [31] \\
\hline $\begin{array}{l}\text { Stem cell } \\
\text { implantation }\end{array}$ & $\begin{array}{l}\text { Somatic stem cells: epithelial progenitor cells } \\
\text { (eEPC) and endometrial mesenchymal stem } \\
\text { cell (eMSP) populations undergo retrograde } \\
\text { migration into the peritoneum, because of } \\
\text { cervical obstruction by mucus plug. After } \\
\text { migration, they lie dormant until menarche, } \\
\text { when estrogen levels rise and stimulate the } \\
\text { growth of endometriosis. }\end{array}$ & {$[94,95]$} \\
\hline $\begin{array}{l}\text { Coelomic } \\
\text { metaplasia }\end{array}$ & $\begin{array}{l}\text { Strongly accepted for the pathogenesis of } \\
\text { ovarian endometriosis. Here metaplastic } \\
\text { change occurs to the coelomic epithelium, } \\
\text { covering the ovary and the serosa of the } \\
\text { peritoneum, such that peritoneal tissue } \\
\text { transforms into endometrial-like tissue. }\end{array}$ & [96] \\
\hline $\begin{array}{l}\text { Müllerian } \\
\text { remnant } \\
\text { abnormalities }\end{array}$ & $\begin{array}{l}\text { Abnormal differentiation or migration of the } \\
\text { embryonic Müllerian ducts (which develop } \\
\text { into the uterus, fallopian tubes and upper } \\
\text { vagina) cause cells to spread to atypical } \\
\text { pelvic locations, particularly the uterosacral } \\
\text { ligaments and pouch of Douglas. }\end{array}$ & [97-99] \\
\hline
\end{tabular}

\section{Disease Pathogenesis}

Endometriosis is identified as a complex disease given that it lacks a clear process of disease pathogenesis, which subsequently impedes on diagnosis and treatment. The mostwidely supported theory for disease pathogenesis of endometriosis is that of retrograde menstruation (Table 1) [31]. This theory supports the notion that during the normal process of menstruation, there is a reflux of endometrial tissue and cells through the fallopian tubes to the ovaries, where it subsequently enters into the peritoneal cavity and grafts ectopically to genitourinary tissue in the peritoneal cavity.
Burney and Giudice [32] explained that menstrual blood is quite commonly found in the peritoneal fluid of healthy women and this can be a common occurrence in adolescent girls with congenital outflow obstruction. Moreover, retrograde menstruation has been induced in non-human primates, the Papio anubis baboon, through supracervical ligation, which resulted in histologically-confirmed endometriosis [33,34]. However, in challenge to the retrograde flow theory, it is observed that approximately $90 \%$ of women are known to exhibit retrograde menstruation, whilst only $15 \%$ of women have endometriosis [9]. This implies that there are other factors that contribute to the pathogenesis of the disease.

Thus, given that the retrograde menstruation theory is not conclusive, many other theories have been hypothesised. These include the stem cell implantation theory, the coelomic metaplasia theory and the Müllerian remnant abnormalities theory summarised in Table 1. Although these theories are supported to a degree by scientific evidence, they lack an absolute association to the development of endometriosis. Despite these proposed theories, a clear definite pathogenesis of endometriosis has yet to be established.

Endometriosis is characterised as an inflammatory condition, given that the peritoneal fluid of women with the disease has a heightened number of activated macrophages, as established through immune-histochemical analysis of endometrial tissue, plasma and peritoneal fluid among women with and without endometriosis [35]. Further associated to the inflammatorystate of endometriosis is an increase in a range of soluble mediators including:

Chemokines: Macrophage inhibitory factor (MIF), MCP-1, RANTES [32,36]

Proinflammatory cytokines: TNF- $\alpha$, IL-6, IL-1 $\beta$, INF- $\gamma$ IL-8, IL-9, IL-17 [37,38].

Growth factors: Platelet-derived growth factor (PDGF), nerve growth factor (NGF) and fibroblast growth factor (FGF), also angiogenic and neurogenic factors, G-CSF [38].

Increased nuclear factor kappa beta (NF-kB) activation has been observed in peritoneal macrophages and peritoneal endometriotic lesions of patients with endometriosis resulting in up-regulation of inflammation and cell proliferation and down-regulation of endometrial cell apoptosis [39-41].

Genome-wide association studies have established certain single nucleotide polymorphisms (SNPs) associated with the disease, namely those found on chromosomes near Wnt4, Greb1, Vezt and Kdr genes as summarised in Table 2 [42-50]. How these putative susceptibility genes impact on the establishment of ectopic tissue growth or on the immune inflammatory responses within the affected individual is currently not understood. With significant correlations found between SNPs and endometriosis, genetic factors are regarded as important contributors to the development of the disease.

\section{Animal Models of Endometriosis}

One of the major barriers to understanding the cellular, molecular and genetic basis of disease pathogenesis for 
endometriosis is the lack of a suitable animal model. Nonhuman primates have been used extensively as a model of the disease and as preclinical models, due to their spontaneous development of endometriosis. Moreover, endometriosis can also be established in non-human primates through the induction of retrograde menstruation [51]. Non-human primates are considered the most suitable model for the study of endometriosis, yet there are ethical and high-cost limitations that limit their use. Murine models offer an alternative for the study of endometriosis as they are more cost-effective and easily maintained. However, mice are unable to develop endometriosis spontaneously as they lack the ability to menstruate.

Table 2. Single nucleotide polymorphisms (SNPS) in genes associated with endometrosis.

\begin{tabular}{|c|c|c|c|}
\hline Gene & Role & $\begin{array}{l}\text { SNPs in } \\
\text { endometrio } \\
\text { sis }\end{array}$ & $\begin{array}{l}\text { Role in } \\
\text { endometriosis }\end{array}$ \\
\hline WNT4 & $\begin{array}{l}\text { A ligand of the Wht signalling } \\
\text { pathway. Associated with the } \\
\text { normal development of the } \\
\text { female reproductive tract, } \\
\text { follicular development, } \\
\text { steroidogenesis and with } \\
\text { endometrium proliferation, } \\
\text { decidualisation } \\
\text { implantation. }\end{array}$ & $\begin{array}{l}\text { rs16826658 } \\
\text { (noncoding) } \\
\text { rs3820282 } \\
\text { (noncoding) }\end{array}$ & $\begin{array}{l}\text { WNT4 protein } \\
\text { expression } \\
\text { downregulated }\end{array}$ \\
\hline $\begin{array}{l}\text { GREB1- } \\
\text { Growth } \\
\text { Regulatio } \\
\mathrm{n} \quad \text { by } \\
\text { Estrogen } \\
\text { in Breast } \\
\text { Cancer } 1\end{array}$ & $\begin{array}{l}\text { Encodes a protein that is a co- } \\
\text { activator of estrogen receptor- } \alpha \\
(\text { ER- } \alpha \text { ) transcription factor. } \\
\text { Promotes estrogen induced } \\
\text { growth. }\end{array}$ & $\begin{array}{l}\text { rs13394619 } \\
\text { (noncoding) } \\
\text { rs1898003 } \\
\text { (noncoding) } \\
\text { rs11674184 } \\
\text { (noncoding) } \\
\text { rs1865574 } \\
\text { (noncoding) } \\
\text { rs2884374 } \\
\text { (noncoding) }\end{array}$ & $\begin{array}{l}\text { Increased gene } \\
\text { expression } \\
\text { ectopic } \\
\text { endometrial tissue }\end{array}$ \\
\hline
\end{tabular}

\begin{tabular}{|c|c|c|c|}
\hline VEZT & $\begin{array}{l}\text { Encodes the adherens junction } \\
\text { transmembrane protein vezatin } \\
\text { that plays a role in cell-cell } \\
\text { adhesion during } \\
\text { embryogenesis. The protein can } \\
\text { also enter the nucleus and } \\
\text { regulate the expression of } \\
\text { target genes for cell adhesion } \\
\text { and invasion. It has also been } \\
\text { suggested as a tumour } \\
\text { suppressive gene. }\end{array}$ & $\begin{array}{l}\text { rs10859871 } \\
\text { (noncoding) }\end{array}$ & $\begin{array}{l}\text { Increased VEZT } \\
\text { protein expression } \\
\text { in blood and } \\
\text { endometrium }\end{array}$ \\
\hline $\begin{array}{l}\text { KDR- } \\
\text { Kinase } \\
\text { Insert } \\
\text { Domain } \\
\text { Receptor }\end{array}$ & $\begin{array}{l}\text { Encodes vascular endothelial } \\
\text { growth factor (VEGF) receptor } \\
2 \text {. This protein is the main } \\
\text { signal transducer in the VEGF/ } \\
\text { VEGF receptor signaling } \\
\text { pathway, responsible for } \\
\text { inducing angiogenesis. }\end{array}$ & $\begin{array}{l}\text { rs17773813 } \\
\text { (noncoding) }\end{array}$ & $\begin{array}{l}\text { Increased } \\
\text { expression of } \\
\text { VEGF receptor } 2 \\
\text { in blood vessels in } \\
\text { endometrium }\end{array}$ \\
\hline
\end{tabular}

In order to replicate the disease in mice, recipient endometrial tissue must be introduced into mice, either from syngeneic animals or through xenogeneic donor tissue [51,52]. However, recent discoveries have identified the spiny mouse (Acomys cahirinus) as the first rodent species known to menstruate spontaneously, with subsequent cyclic endometrial shedding and repair [53]. This provides a more suitable, yet still accessible and cost-effective murine model for the future study of endometriosis. A significant limitation with the spiny mouse strain is that it is an outbred strain which would limit the capacity to transfer cells or tissues between the spiny mouse and other inbred strains. The development of gene editing technology through the CRISPR-Cas9 system would offer one potential method by which specific gene mutations could be introduced into the spiny mouse strain and the mutations could be evaluated for their ability to induce endometriosis and its impact on innate and adaptive immune responses in vivo.

\section{Host Microbiota}

The healthy human body comprises of a unique, diverse and relatively stable habitation of microorganisms (bacteria, eukaryotes, archaea and viruses), whose symbiotic relationship with the host contributes to general health and wellbeing. These microorganisms that reside in and on the human body are collectively termed 'microbiota,' with their assembled genomic sequences termed 'microbiome'. The importance of microbiota to human health and physiology is essential, so much so that an individual's collective microbial community has previously been regarded as a 'neglected' and 'forgotten' organ [22-24]. The significance of an individual's microbiota stems from its physiological, immunological and metabolic functional capacity [21].

To further define the importance of an individual's microbiota, an imbalance or disruption to an otherwise commensal or mutualistic relationship with the human host, results in a state of microbial dysbiosis which can affect host biology and contribute to disease. Following the direction of Robert Koch in 1890, with his postulations that microorganisms were causative agents for disease, many contemporary diseases have been associated with microbial level-changes [25]. For instance, microbial dysbiosis has been associated with inflammatory bowel disease including Crohn's disease and ulcerative colitis [26], metabolic disease such as obesity [27] and type 2 diabetes [28], asthma [54], breast cancer [55], autoimmune disease [29,30], allergies [56] and autism spectrum disorder[57]. These growing correlations between microbial dysbiosis and disease are a product of an early $21 \mathrm{st}$ century scientific momentum to re-evaluate the role of microbiota in human health [58]. This topical approach to understanding disease has been made possible through advancements in high-throughput metagenomic sequencing technology alongside global efforts to characterise the healthy human microbiome [58].

\section{Genitourinary Microbiota and Dysbiosis of the Microflora}

The colonisation of microorganisms in and on body surfaces occurs at birth, with the in-utero environment considered axenic (germ free) [59-61]. It has been reported that infants are initially exposed to microorganisms upon birth, with maternal cervical mucus and immunoglobulins, as well as the placenta, providing a degree of barrier defence and antimicrobial activity from ascending vaginal infective agents [62]. 
Citation: Puca J, Hoyne GF. Microbial dysbiosis and disease pathogenesis of endometriosis, could there be a link?. Allied J Med Res 2017;1(1):1-9.

Recent scientific efforts to characterise the human microbiome have determined key microorganisms that constitute the vaginal flora. Lactobacilli species were the most dominant species and their ability to produce lactic acid subsequently contributes to the low $\mathrm{pH}$ of the vagina (Figure 1) [63]. Furthermore, hormonal changes associated with the menstrual cycle have been shown to alter the composition of the vaginal microbiome. Varying levels of estrogen and progesterone have been reported to impede on microbial flora stability, particularly during menses when the flora presents with a lack of stability. However, hormonally fluctuated microbial community changes occur without effecting the functional and metabolic capacity of the vaginal flora [64].

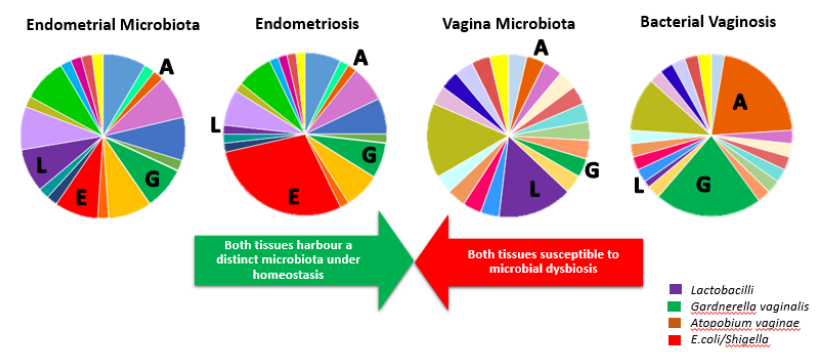

Figure 1. Summary of the microbial dysbiosis that occurs in response to endometriosis and bacterial vaginosis. The pie charts show representations of various microbial species within the endometrium and vagina of females in health disease - For simplicity we have focused on 4 main species Lactobacilli (purple), Gardnerella vaginalis (green) Atopobium vaginae (brown) and E. coli/Shigella which are members of the Enterobactericiae family (red) that are discussed in the text. The microbiota of women with endometriosis show a large expansion of E. coli/Shigella which are pathogenic and a reduction in the proportion of Lactobacilli spp. compared to healthy endometrium. In women with bacterial vaginosis there is an expansion of Gardnerella vaginalis and Atopobium vaginae species at the expense of Lactobacilli which could facilitate local tissue inflammation. The charts highlight that both the endometrium and vagina have a distinct microflora during normal tissue homeostasis, but this can change during the onset of disease such as endometriosis or bacterial vaginosis respectively.

Microbial dysbiosis is not an alien term when discussing diseases of the female reproductive tract. In fact, particular gynaecological diseases have been shown to develop in response to bacterial imbalances that can lead to bacterial vaginosis. Bacterial vaginosis is a bacterial infection of the vagina that commonly presents as abnormal grey vaginal discharge with a strong unusual 'fishy' odour. This disease can cause discomfort and unease in affected women and can reduce the frequency of successful pregnancy in patients undergoing in-vitro fertilisation (IVF) [65] and is also associated with premature births [66,67]. Lactobacilli spp. are the most abundant commensal bacteria in the vagina and the clinical onset of bacterial vaginosis is characterised by a decrease in the population of Lactobacilli species [65]. In contrast there is a substantial increase in growth of residing anaerobic or facultative anaerobic bacteria, such as Gardnerella vaginalis and Atopobium vaginae (Figure 1). This microbial population shift introduces heterogeneity into the resident microbial community, resulting in microbial imbalance and subsequent disease $[65,67]$.

Table 3. Bacterial species identified in the endometrium.

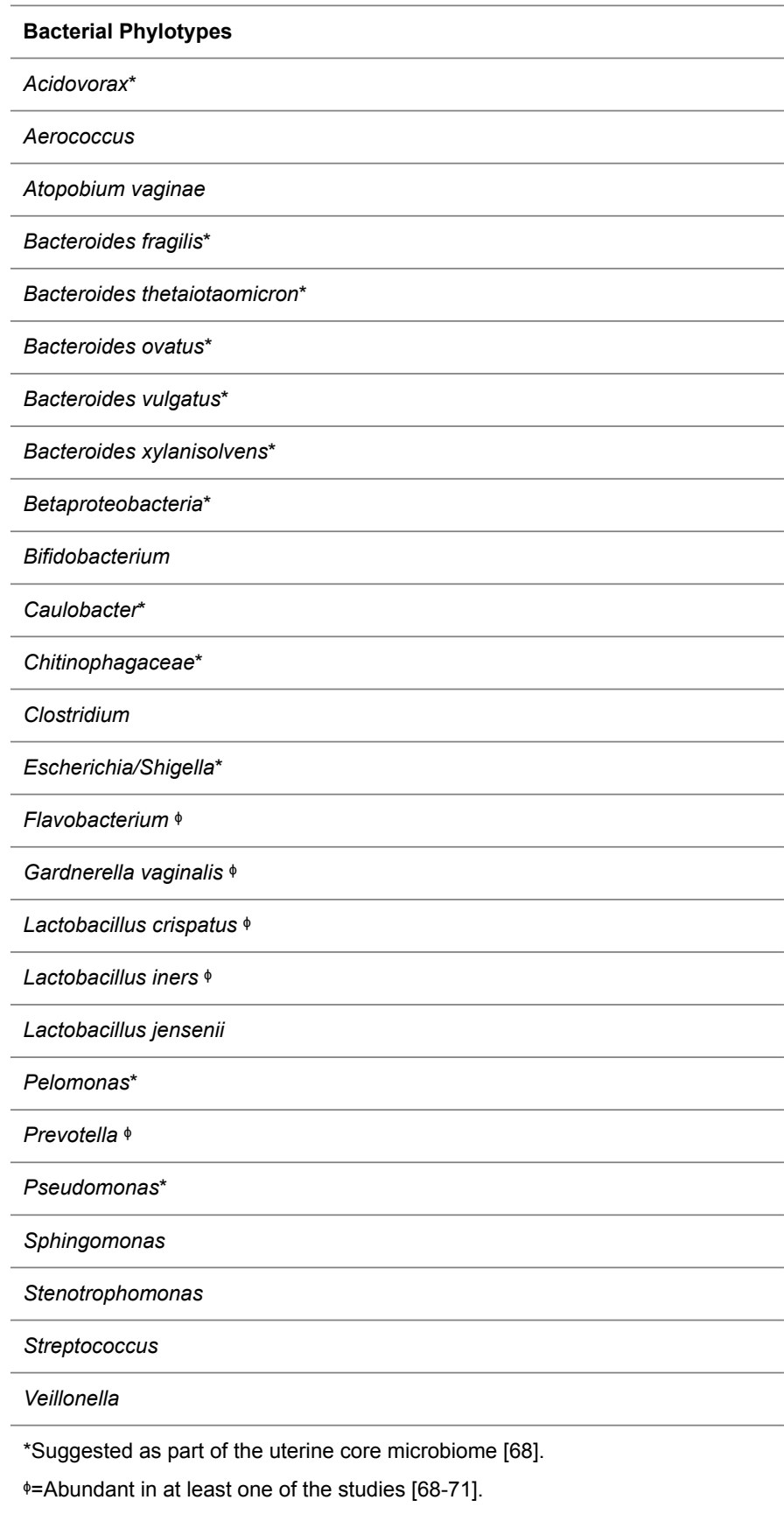

Recently Verstraelen et al. [68] examined the resident microbiota of the endometrium through $16 \mathrm{~S}$ ribosomal RNA (16S rRNA) metagenomic sequencing of endometrial samples. They identified 183 different bacterial phylotypes, of which 15 had an abundance greater than $1 \%$ among the test subjects. The authors identified a 'uterine core microbiome' that not only enforces the presence of microorganisms in the endometrium, but further suggests a consistency of bacterial phylotypes among individuals. Belonging to this uterine core microbiome were bacteria from the Proteobacteria, Firmicutes and predominantly Bacteroidetes phyla (Figure 1 and Table 3). These findings have been supported by three independent 
analyses that examined the composition of the uterine microbiota [69-71]. Brewster, et al. [72] examined the bacterial microbiome of fallopian tubes, fimbriae and ovaries and showed these various tissues harboured a significantly unique bacterial microbiome. Additionally, Pelzer et al. [73] revealed the characteristics of the microbiome of follicular fluid which provided insight into the microbial colonisation of the ovaries. Although contamination is common among the microorganisms of the vagina and follicular fluid, Pelzer et al. [73] identified that the microbiota of follicular fluid was distinct and unique to that of the vagina in some patients. Predominant species identified were Lactobacillus iners, Actinomyces spp., Corynebacterium auromucosum, Fusobacterium spp., Peptinophilus asaccharolyticus, Peptostreptococcus spp., Propionibacterium spp. Prevotella spp., Staphylococcus spp., and the yeast Candida parapsilosi.

\section{The Role of Lactobacillus species in the Vaginal Microflora}

Resident vaginal Lactobacilli spp. have been shown to reduce infection of pathogens and protect against microbial dysbiosis [74]. This protection is achieved through the general ability of Lactobacilli spp. to biosynthesise products of lactic acid, hydrogen peroxide $\left(\mathrm{H}_{2} \mathrm{O}_{2}\right)$ and antimicrobial compounds, which act to inhibit the growth of pathogens (Figure 2) [75]. Lactic acid is the primary microbicide agent produced by Lactobacilli spp. and is responsible for maintaining a low $\mathrm{pH}$ environment, creating an unfavourable milieu for many bacterial species [76]. The acidification driven by Lactobacilli spp. has been shown to directly inhibit the growth of pathogens $[74,75,77]$. Accompanying lactic acid, is the production $\mathrm{H}_{2} \mathrm{O}_{2}$, which further acts to inhibit the growth of pathogens. $\mathrm{H}_{2} \mathrm{O}_{2}$ generates reactive oxygen species and induces oxidative stress which results in DNA damage and bacterial lethality [78]. It seems that Lactobacilli spp. are themselves protected from this $\mathrm{H}_{2} \mathrm{O}_{2}$ through the expression of anti-oxidative enzymes including catalase, superoxide dismutase 2 and glutathione peroxidase-1 [79]. Furthermore, $\mathrm{H}_{2} \mathrm{O}_{2}$ enhances host production of antimicrobial peptides secreted by epithelial cells, namely muramidase and lactoferrin (Figure 2). Muramidase is an enzyme that hydrolyses and thus cleaves the bacterial cell wall component peptidoglycan, inhibiting bacterial growth and survival, particularly that of gram positive bacteria [80]. Many, but not all, Lactobacilli spp. have a constitutively expressed proteinaceous surface layer (S-layer), that non-covalently binds to peptidoglycan and envelopes the entire cell wall $[81,82]$. This S-layer is often associated with a protective function and could thus infer protection from muramidase activity and other bacteriolytic enzymes [82]. On the other hand, lactoferrin, a host-derived glycoprotein, acts by binding to lipopolysaccharide (LPS), a component of the cell wall of gram negative that is absent in gram positive Lactobacilli spp., destabilising it and increasing the permeability of the bacterial outer membrane to surrounding intrinsic bactericidal agents [83]. Interestingly, decreased lactoferrin levels have been detected in the peritoneal fluid of women with endometriosis [84]. Not only does this support reduced Lactobacilli spp. abundance in women with endometriosis, it further reveals that women with endometriosis have a reduced anti-bactericidal capacity, which could further promote microbial dysbiosis. However, it remains unclear whether decreased lactoferrin levels indicate reduced Lactobacilli spp. abundance in the endometrium or the peritoneal cavity, making it difficult to ascertain where the microbial dysbiosis takes place.

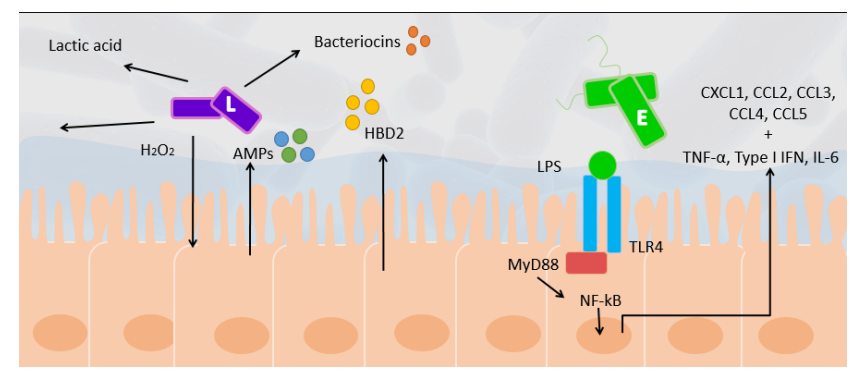

Figure 2. Mucosal immune regulation induced by the microbial flora within the female reproductive system. Lactobacilli spp. dominate the normal microflora in the vagina and endometrium of healthy women. These organisms can secrete lactic acid to reduce the local $\mathrm{pH}$ as well as $\mathrm{H}_{2} \mathrm{O}_{2}$ and bacteriocins that reduce the growth of microbial species.In addition, the presence of Lactobacilli can induce the secretion of antimicrobial peptides (AMPs) that include human beta defensins from epithelial cells that can directly impact on the composition and diversity of the local microflora. Emergence of pathogenic E. coli/Shigella spp. can lead to the release of lipopolysaccharide (LPS) which can bind to pattern recognition receptors (e.g. Toll-like receptor 4) on the surface of epithelial cellsto induce signalling and the release of pro-inflammatory cytokines (TNF-a, Type 1 IFN and IL-6) and chemokines that promote recruitment of inflammatory cells to the site of infection. If the microbial dysbiosis is not corrected then this could lead to chronic inflammation in the reproductive tract.

In addition to lactic acid and $\mathrm{H}_{2} \mathrm{O}_{2}$, Lactobacilli spp. have been found to produce a range of bacteriocins (bacteria-derived antimicrobial agents) that further inhibit the growth of surrounding bacterial and fungal pathogens [85,86]. For instance, L. acidophilus, produces the bacteriocin Acidophillin 801 which has a narrow inhibitory spectrum of activity against gram negative bacteria as well as some other Lactobacilli spp. [81] (Figure 2). L. acidophilus contains a S-layer that is believed to infer protection from biosynthesised bacteriocins [81]. Whilst different species vary in their capacity to produce these antimicrobial agents, the core microbiota Lactobacilli spp. population provides a collective effort to protect against pathogens and prevent subsequent microbial dysbiosis. These findings assert the importance of Lactobacilli spp. in the endometrium and their corresponding biosynthesised products in protecting against pathogens.

\section{Bacterial Vaginosis and Microbial dysbiosis}

Given that endometrial ectopic tissue has been found in the surrounding genitourinary region, as a result of retrograde menstruation, it raises a hypothesis that maybe the development of endometriosis could arise from a microbial dysbiosis. This concept has been identified more frequently and characterised in more detail with gastrointestinal diseases such as Crohn's Disease and Ulcerative Colitis [26]. Given the 
Citation: Puca J, Hoyne GF. Microbial dysbiosis and disease pathogenesis of endometriosis, could there be a link?. Allied J Med Res 2017;1(1):1-9.

proximity of the vagina to the uterus, and the recent characterisation of the microbiota along with different areas of the reproductive tract, it warrants consideration to the influence that a microbial dysbiosis might have on disease pathogenesis of endometriosis. Gynaecological diseases such as bacterial vaginosis have been shown to develop in response to an imbalance of bacterial species. As seen in Figure 1, bacterial vaginosis specifically involves a decrease in Lactobacilli spp. and an increase in growth of residing anaerobic or facultative anaerobic bacteria, including Gardnerella vaginalis and Atopobium vaginae. The ascent, introduction and domination of certain sexually transmitted microorganisms including Chlamydia trachomatis and Neisseria gonorrhoeae, pathogenic Escherichia coli, or bacterial vaginosis-related species act to alter the reproductive tract microbiota, enforcing microbial dysbiosis and subsequent disease [87-89].

Although microbial dysbiosis has been associated with other gynaecological diseases, it has been poorly investigated in relation to endometriosis. Nonetheless, several studies have attempted to characterise the endometrial microbiome of women with endometriosis and investigate the role of bacteria in relation to the disease. Khan et al. [90], utilising 16s rRNA genomic sequencing, identified a significant increase in Streptococcaceae in samples from women with endometriosis, compared to control samples. The same study also recognized a slight increase in Moraxellaceae and a modest decrease in Lactobacillaceae in women with endometriosis, though these differences were statistically insignificant.

Khan et al. [91] found that women with endometriosis had a significant increase in E. coli in menstrual blood and endotoxin levels in menstrual and peritoneal fluid. Following this, Khan et al. [92] further revealed that endometriosis was accompanied by an increase in Gardnerella, Group A-Streptococcus, Enterococci and E. coli upon the culturing of endometrial samples on culture medium. Although quantity of bacterial growth was measured, rather than specificity of bacterial species, culture-dependent techniques still warrant caution when accepting these results. Nonetheless, excess growth of certain bacterial species or an imbalance of commensal bacteria could contribute to the development of endometriosis.

Moreover, Khan et al. [92] also found that women with endometriosis were more predisposed to a higher vaginal $\mathrm{pH}$ $(\geq 4.5)$ than in control subjects, inferring that this greater diversity of bacterial species in women with endometriosis was permitted due to an altered vaginal environment. This suggests that women with endometriosis could have a reduced lacticacid producing bacterial population, namely Lactobacilli spp., increasing the susceptibility to microbial imbalance and dysbiosis. As aforementioned, although the results were not statistically significant, Khan et al. [90] did note a decrease in Lactobacillaceae in women with endometriosis. This decrease was also commonly seen in women with bacterial vaginosis, supporting the notion that perhaps altered Lactobacilli spp. levels contribute to the development of endometriosis.

Studies investigating endometriosis in non-human primates have shed similar insights into a dysbiosis of endometrium. Bailey and Coe [93] examined the concentration of popular bacterial species in the shed endometrium of female rhesus monkeys with endometriosis by means of culture-dependent techniques. It was found that rhesus monkeys with endometriosis had reduced Lactobacilli spp. concentrations, whilst presenting an increased concentration of gram negative anaerobic and facultative anaerobic bacteria. As samples were not taken directly from the endometrium, but instead from shed endometrium, this might not be an accurate characterisation of endometriosis-associated endometrium microbiota. However, despite the method of sample obtainment and the results being obtained from non-human primates, they resemble the findings presented in human studies $[92,90]$.

\section{Conclusion}

Whilst microbial dysbiosis in relation to the development of endometriosis is quite a novel concept, the collective and comprehensive analysis of several direct and multiple indirect studies have allowed for an evaluation of the topic. It has been demonstrated that the endometrium harbours a microbiota and is thus susceptible to dysbiosis, although further microbiome characterisation of the peritoneal cavity and deeper genitourinary regions is poor. Additionally, microbial dysbiosis has been shown to be responsible for other gynaecological diseases, making it reasonable to deduce that microbial dysbiosis could contribute to the disease in question. Moreover, key microbes were identified in women with endometriosis, implying that endometriosis or at least the inflammatory property of endometriosis is a result of microbial imbalance. Of particular interest was reduced Lactobacilli spp. abundance accompanied by a high $\mathrm{pH}$ environment as well as an increase in gram negative bacteria abundance, commonly $E$. coli. This shift in the microbial population was shown to have the capacity to reduce host immunological capability and induce host susceptibility to pathogens. This inference supports the retrograde menstruation theory crediting the probability of retrograde migration of pathogenic bacteria into the endometrium and ectopic endometrial tissue to atypical sites and further appreciates that genetic susceptibility may also play a role in the development of the disease, in conjunction with microbial dysbiosis. Ultimately, it seems plausible that the pathogenesis of endometriosis could be related to microbial dysbiosis, predominately centred around a reduced commensal-associated immune capability as well as an ascending microbial infection. This could have important implications for the treatment of endometriosis in the future.

\section{Acknowledgements}

We would like to acknowledge grant support of the Juvenile Diabetes Research Foundation (4-2006-1025) and Diabetes Research Foundation of Western Australia awarded to GFH.

\section{References}

1. Gylfason JT, Kristjansson KA, Sverrisdottir G, et al. Pelvic endometriosis diagnosed in an entire nation over 20 years. Am J Epidemiol. 2010;172:237-43.

2. Leibson CL, Good AE, Hass SL, et al. Incidence and characterization of diagnosed endometriosis in a 
geographically defined population. Fertil Steril. 2004;82:314-21.

3. Morassutto C, Monasta L, Ricci G, et al. Incidence and estimated prevalence of endometriosis and adenomyosis in Northeast Italy: A data linkage study. PLoS ONE. 2016;11:e0154227.

4. Mowers EL, Lim CS, Skinner B, et al. Prevalence of endometriosis during abdominal or laparoscopic hysterectomy for chronic pelvic pain. Obstet Gynecol. 2016;127:1045-53.

5. Vezzoli F, Mezzanotte C, Vercellini P, et al. Prevalence and anatomical distribution of endometriosis in women with selected gynaecological conditions: Results from a multicentric Italian study. Hum Reprod. 1994;9:1158-62.

6. Ballard KD, Seaman HE, De Vries CS, et al. Can symptomatology help in the diagnosis of endometriosis? Findings from a national case-control study - Part 1. Brit J Obstet Gynaec. 2008;115:1382-91.

7. Giudice LC. Endometriosis. New Engl J Med 2010;362:2389-98.

8. Hickey M, Ballard K, Farquhar C. Endometriosis. Brit Med J. 2014;348:1752.

9. Hogg S, Vyas S. Endometriosis. Obstet Gynaecol Reprod Med. 2015;25:133-41.

10. Viganò P, Parazzini F, Somigliana E, et al. Endometriosis: Epidemiology and aetiological factors. Clin Obstet Gynaecol. 2004;18:177-200.

11. Brosens IA, Puttemans PJ, Deprest J. The endoscopic localization of endometrial implants in the ovarian chocolate cyst. Fertil Steril. 1994;61:1034-8.

12. Sonavane SK, Kantawala KP, Menias CO. Beyond the boundaries-Endometriosis: Typical and atypical locations. Curr Probl Diagn Radiol. 2011;40:219-32.

13. Fourquet J, Baez L, Figueroa M, et al. Quantification of the impact of endometriosis symptoms on health-related quality of life and work productivity. Fertil Steril. 2011;96:107-12.

14. Fritzer N, Haas D, Oppelt P, et al. More than just bad sex: Sexual dysfunction and distress in patients with endometriosis. Eur J Obstet Gynecol Reprod Biol. 2013;169:392-6.

15. Fuldeore M, Yang H, Du EX, et al. Healthcare utilization and costs in women diagnosed with endometriosis before and after diagnosis: A longitudinal analysis of claims databases. Fertil Steril. 2015;103:163-71.

16. Hansen KE, Kesmodel US, Baldursson EB, et al. The influence of endometriosis-related symptoms on work life and work ability: A study of Danish endometriosis patients in employment. Eur J Obstet Gynecol Reprod Biol. 2013;169:331-9.

17. Klein S, D'Hooghe T, Meuleman C, et al. What is the societal burden of endometriosis-associated symptoms? A prospective Belgian study. Reprod BioMed Online. 2014;28:116-24.

18. Levy AR, Osenenko KM, Lozano-Ortega G, et al. Economic burden of surgically confirmed endometriosis in Canada. J Obstet Gynaecol. 2011;33:830-7.
19. Nnoaham KE, Hummelshoj L, Webster P, et al. Impact of endometriosis on quality of life and work productivity: A multicenter study across ten countries. Fertil Steril. 2011;96:366-73

20. Simoens S, Dunselman G, Dirksen C, et al. The burden of endometriosis: Costs and quality of life of women with endometriosis and treated in referral centres. Hum Reprod. 2014; 29: 1292-9.

21. Clemente JC, Ursell LK, Parfrey LW, et al. The impact of the gut microbiota on human health: An integrative view. Cell. 2012;148:1258-70.

22. Baquero F, Nombela C. The microbiome as a human organ. Clinic Microbiol Infect. 2012;18:2-4.

23. Bocci V. The neglected organ: Bacterial flora has a crucial immunostimulatory role. Perspect Biol Med. 1992;35:251-60.

24. O'Hara AM, Shanahan F. The gut flora as a forgotten organ. EMBO Reports. 2006;7:688-93.

25. Rivers TM. Viruses and Koch's Postulates. J Bacteriol. 1937;33:1-12.

26. Couturier-Maillard A, Secher T, Rehman A, et al. NOD2mediated dysbiosis predisposes mice to transmissible colitis and colorectal cancer. J Clin Invest. 2013;123:700-11.

27. Ridaura VK, Faith JJ, Rey FE, et al. Gut microbiota from twins discordant for obesity modulate metabolism in mice. Science. 2013;341:1241214.

28. Qin J, Li Y, Cai Z, et al. A metagenome-wide association study of gut microbiota in type 2 diabetes. Nature. 2012;490:55-60.

29. Hevia A, Milani C, López P, et al. Intestinal dysbiosis associated with systemic lupus erythematosus. MBio. 2014;5:e01548-01514.

30. Lerner A, Aminov R, Matthias T. Dysbiosis may trigger autoimmune diseases via inappropriate post-translational modification of host proteins. Front Microbio. 2016;7:84.

31. Sampson J. Peritoneal endometriosis due to menstrual dissemination of endometrial tissue into the peritoneal cavity. Am J Obstet Gynecol. 1927;14:442-69.

32. Burney RO, Giudice LC. Pathogenesis and pathophysiology of endometriosis. Fertil Steril. 2012;98:511-9.

33. D'Hooghe TM, Bambra CS, Suleman MA et al. Development of a model of retrograde menstruation in baboons (Papio anubis). Fertil Steril. 1994;62:635-8.

34. Dehoux JP, Defrre S, Squifflet J, et al. Is the baboon model appropriate for endometriosis studies? Fertil Steril. 2011;96:728-33.

35. Berbic M, Schulke L, Markham R, et al. Macrophage expression in endometrium of women with and without endometriosis. Hum Reprod. 2009;24:325-32.

36. Rakhila H, Girard K, Leboeuf M, et al. Macrophage migration inhibitory factor is involved in ectopic endometrial tissue growth and peritoneal-endometrial tissue interaction in vivo: A plausible link to endometriosis development. PLoS ONE. 2014;9:e110434.

37. Kang YJ, Jeung IC, Park A, et al. An increased level of IL-6 suppresses NK cell activity in peritoneal fluid of 
Citation: Puca J, Hoyne GF. Microbial dysbiosis and disease pathogenesis of endometriosis, could there be a link?. Allied J Med Res 2017;1(1):1-9.

patients with endometriosis via regulation of SHP-2 expression. Hum Reprod. 2014;29:2176-89.

38. Lessey BA, Nagarkatti M, Zhou J, et al. Peripheral and local cytokines including IL-8, IL-9 AND IL-17 are elevated in endometriosis: An in vivo and in vitro analysis before and after surgery suggests a mechanism for endometrial dysfunction. Fertil Steril. 2012;98:92.

39. Gonzalez-Ramos R, Langendonckt AV, Defrre S, et al. Involvement of the nuclear factor-kB pathway in the pathogenesis of endometriosis. Fertil Steril. 2010;94:1985-94.

40. González-Ramos R, Defrère S, Devoto L. Nuclear factorkappaB: A main regulator of inflammation and cell survival in endometriosis pathophysiology. Fertil Steril. 2012;98:520-28.

41. Lousse JC, Langendonckt VA, González-Ramos R, et al. Increased activation of nuclear factor-kappa B (NF-?B) in isolated peritoneal macrophages of patients with endometriosis. Fertil Steril. 2008;90:217-20.

42. Fung JN, Holdsworth-Carson SJ, Sapkota Y, et al. Functional evaluation of genetic variants associated with endometriosis near GREB1. Hum Reprod 2015;30:1263-75.

43. Liang Y, Li Y, Liu K, et al. Expression and significance of WNT4 in ectopic and eutopic endometrium of human endometriosis. Reprod Sci. 2016;23:379-85.

44. Mafra F, Catto M, Bianco B, et al. Association of WNT4 polymorphisms with endometriosis in infertile patients. J Assist Reprod Genet. 2015;32:1359-64.

45. Miao R, Guo X, Zhi Q, et al. VEZT, a novel putative tumor suppressor, suppresses the growth and tumorigenicity of gastric cancer. PLoS One. 2013;8:e74409.

46. Mohammed H, D'Santos C, Serandour AA, et al. Endogenous purification reveals GREB1 as a key estrogen receptor regulatory factor. Cell Reports. 2013;3:342-9.

47. Nyholt DR, Low SK, Anderson CA, et al. Genome-wide association meta-analysis identifies new endometriosis risk loci. Nat Genet. 2012;44:1355-9.

48. Pagliardini L, Gentilini D, Sanchez AM, et al. Replication and meta-analysis of previous genome-wide association studies confirm vezatin as the locus with the strongest evidence for association with endometriosis. Hum Reprod. 2015;30:987-93.

49. Pellegrini C, Gori I, Achtari C, et al. The expression of estrogen receptors as well as GREB1, c-MYC, and cyclin $\mathrm{D} 1$, estrogen-regulated genes implicated in proliferation, is increased in peritoneal endometriosis. Fertil Steril. 2012;98:1200-8.

50. Steinthorsdottir V, Thorleifsson G, Aradottir K, et al. Common variants upstream of KDR encoding VEGFR2 and in TTC39B associate with endometriosis. Nat Commun. 2016;7:12350.

51. Tirado-Gonzalez I, Barrientos G, Tariverdian N, et al. Endometriosis research: Animal models for the study of a complex disease. J Reprod Immunol. 2010;86:141-7.

52. Greaves E, Cousins FL, Murray A et al. A novel mouse model of endometriosis mimics human phenotype and reveals insights into the inflammatory contribution of shed endometrium. Am J Pathol. 2014;184:1930-9.

53. Bellofiore N, Ellery SJ, Mamrot J, et al. First evidence of a menstruating rodent: The spiny mouse (Acomys cahirinus). Am J Obstet Gynecol. 2016.

54. Bisgaard H, Hermansen MN, Buchvald F, et al. Childhood asthma after bacterial colonization of the airway in neonates. N Engl J Med. 2007;357:1487-95.

55. Xuan C, Shamonki JM, Chung A, et al. Microbial dysbiosis is associated with human breast cancer. PLoS One. 2014;9:e83744.

56. Rachid RA, Gerber G, Li N, et al. Food allergy in infancy is associated with dysbiosis of the intestinal microbiota. J Allergy Clin Immun. 2016;137.

57. Adams JB, Johansen LJ, Powell LD, et al. Gastrointestinal flora and gastrointestinal status in children with autismComparisons to typical children and correlation with autism severity. BMC Gastr. 2011;11:22.

58. NIH HMP Working Group, Peterson J, Garges S, et al. The NIH Human Microbiome Project. Genome Res. 2009;19:2317-23.

59. Bäckhed F, Roswall J, Peng Y, et al. Dynamics and stabilization of the human gut microbiome during the first year of life. Cell Host Microbe. 2015;17,690-703.

60. Koenig JE, Spor A, Scalfone N, et al. Succession of microbial consortia in the developing infant gut microbiome. P Natl Acad Sci USA. 2011;108:4578-85.

61. Yatsunenko T, Rey FE, Manary MJ, et al. Human gut microbiome viewed across age and geography. Nature. 2012;486:222-7.

62. Hansen LK, Becher N, Bastholm S, et al. The cervical mucus plug inhibits, but does not block, the passage of ascending bacteria from the vagina during pregnancy. Acta Obstet Gyn Scan. 2014;93:102-8.

63. Ravel J, Gajer P, Abdo Z, et al. Vaginal microbiome of reproductive-age women. Proc Natl Acad Sci U S A. 2011;108:4680-7.

64. Gajer P, Brotman RM, Bai G, et al. Temporal dynamics of the human vaginal microbiota. Sci Translation Med. 2012;4:132.

65. Haahr T, Jensen JS, Thomsen L, et al. Abnormal vaginal microbiota may be associated with poor reproductive outcomes: A prospective study in IVF patients. Hum Reprod. 2016;31:795-803.

66. Kindinger LM, MacIntyre DA, Lee YS, et al. Relationship between vaginal microbial dysbiosis, inflammation, and pregnancy outcomes in cervical cerclage. Sci Translation Med. 2016;8:102.

67. Lamont RF, Sobel JD, Akins RA, et al. The vaginal microbiome: New information about genital tract flora using molecular based techniques. Brit J Obstet Gynaec. 2011;118:533-49.

68. Verstraelen H, Vilchez-Vargas R, Desimpel F, et al. Characterisation of the human uterine microbiome in nonpregnant women through deep sequencing of the V1-2 region of the 16S rRNA gene. Peer J. 2016;4:e1602. 
69. Franasiak JM, Tao X, Lonczak A, et al. Characterizing the uterine microbiome: Next generation sequencing of the V4 region of the $16 \mathrm{~S}$ ribosomal gene. Fertil Steril. 2014;102:e135-e136.

70. Franasiak JM, Werner MD, Juneau CR, et al. Endometrial microbiome at the time of embryo transfer: Next-generation sequencing of the $16 \mathrm{~S}$ ribosomal subunit. J Assist Reprod Gen. 2016;33:129-36.

71. Mitchell CM, Haick A, Nkwopara E, et al. Colonization of the upper genital tract by vaginal bacterial species in nonpregnant women. Am J Obstet Gynecol. 2015;212:1-9.

72. Brewster WR, Ko EM, Keku TOK. An evaluation of the microbiota of the upper genital tract of women with benign changes and epithelial ovarian cancer. J Clin Oncol. 2016;34.

73. Pelzer ES, Allan JA, Cunningham K, et al. Microbial colonization of follicular fluid: Alterations in cytokine expression and adverse assisted reproduction technology outcomes. Hum Reprod. 2011;26:1799-812.

74. Mastromarino P, Pietro MD, Schiavoni G, et al. Effects of vaginal lactobacilli in Chlamydia trachomatis infection. Int J Med Microbio. 2014;304:654-61.

75. Dasari S, Shouri RND, Wudayagiri R, et al. Antimicrobial activity of Lactobacillus against microbial flora of cervicovaginal infections. Asian Pac J Trop Dis. 2014;4:18-24.

76. O'Hanlon DE, Moench TR, Cone RA. Vaginal $\mathrm{pH}$ and microbicidal lactic acid when lactobacilli dominate the microbiota. PLoS One. 2013;8:e80074.

77. Graver MA, Wade JJ. The role of acidification in the inhibition of Neisseria gonorrhoeae by vaginal lactobacilli during anaerobic growth. Annals Clin Microbio Antimicrob. 2011;10:8.

78. Martín R, Suárez JE. Biosynthesis and degradation of $\mathrm{H} 2 \mathrm{O} 2$ by vaginal lactobacilli. Appl Environ Microbiol. 2010;76:400-5.

79. Achuthan AA, Duary RK, Madathil A, et al. Antioxidative potential of lactobacilli isolated from the gut of Indian people. Mol Biol Rep. 2012;39:7887-97.

80. Mercier C, Domakova E, Tremblay J, et al. Effects of a muramidase on a mixed bacterial community. FEMS Microbiol Lett. 2000; 187:47-52.

81. Grosu-Tudor SS, Brown L, Hebert EM, et al. S-layer production by Lactobacillus acidophilus IBB 801 under environmental stress conditions. Appl Microbiol Biot. 2016;100:4573-83.

82. Hynönen U,Palva A. Lactobacillus surface layer proteins: Structure, function and applications. Appl Microbiol Biot. 2013;97:5225-43.

83. Drago-Serrano ME, Garza-Amaya DLM, Luna JS, et al. Lactoferrin-lipopolysaccharide (LPS) binding as key to antibacterial and antiendotoxic effects. Int Immunopharm. 2012;12:1-9.

84. Polak G, Wertel I, Tarkowski R, et al. Decreased lactoferrin levels in peritoneal fluid of women with minimal endometriosis. Eur J Obstet Gyn R B. 2007;131:93-6.
85. Cortés-Zavaleta O, López-Malo A, Hernández-Mendoza A, et al. Antifungal activity of lactobacilli and its relationship with 3-phenyllactic acid production. Int J Food Microbiol. 2014;173:30-5.

86. Elayaraja S, Annamalai N, Mayavu P, et al. Production, purification and characterization of bacteriocin from Lactobacillus murinus AU06 and its broad antibacterial spectrum. Asian Pac J Trop Biomed. 2014;4:305-11.

87. Brunham RC, Gottlieb SL, Paavonen J. Pelvic inflammatory disease. N Engl J Med. 2015; 372: 2039-48.

88. Green KA, Zarek SM, Catherino WH. Gynecologic health and disease in relation to the microbiome of the female reproductive tract. Fertil Steril. 2015;104:1351-7.

89. Sheldon IM, Rycroft AN, Dogan B, et al. Specific strains of Escherichia coli are pathogenic for the endometrium of cattle and cause pelvic inflammatory disease in cattle and mice. PLoS ONE. 2010;5:e9192.

90. Khan KN, Fujishita A, Masumoto H, et al. Molecular detection of intrauterine microbial colonization in women with endometriosis. Europ J Obstet Gynecol Reprod Bio. 2016;199:69-75.

91. Khan KN, Kitajima M, Hiraki K, et al. Escherichia coli contamination of menstrual blood and effect of bacterial endotoxin on endometriosis. Fertil Steril. 2010;94:2860-3.

92. Khan KN, Fujishita A, Kitajima M, et al. Intra-uterine microbial colonization and occurrence of endometritis in women with endometriosisâ. Hum Reprod. 2014;29:2446-56.

93. Bailey MT, Coe CL. Endometriosis is associated with an altered profile of intestinal microflora in female rhesus monkeys. Hum Reprod. 2002;17:1704-8.

94. Gargett CE, Schwab KE, Brosens JJ, et al. Potential role of endometrial stem/progenitor cells in the pathogenesis of early-onset endometriosis. Mo Hum Reprod. 2014;20:591-8.

95. Sasson IE, Taylor HS. Stem cells and the pathogenesis of endometriosis. Ann Ny Acad Sci. 2008;1127:106-15.

96. Matsuura K, Ohtake H, Katabuchi H, et al. Coelomic metaplasia theory of endometriosis: Evidence from in vivo studies and an in vitro experimental model. Gynecol Obstet Inves. 1999;47:18-22.

97. Kaufman Y, Lam A. The pelvic uterus-like mass - A primary or secondary müllerian system anomaly? J Min Inv Gynecol. 2008;15:494-7.

98. Olive DL, Henderson DY. Endometriosis and mullerian anomalies. Obstetrics and Gynecology. 1987;69:412-5.

99. Ugur M, Turan C, Mungan T, et al. Endometriosis in association with mullerian anomalies. Gynecol Obstet Inves. 1995;40:261-4.

\section{*Correspondance to}

Gerard Hoyne,

School of Health Sciences,

University of Notre Dame Australia,

Western Australia. 